\title{
Androgen actions in the ovary: balance is key
}

\author{
Hen Prizant ${ }^{1}$, Norbert Gleicher ${ }^{2}$ and Aritro Sen ${ }^{1,2}$ \\ ${ }^{1}$ Division of Endocrinology and Metabolism, Department of Medicine, University of Rochester School of Medicine \\ and Dentistry, 601 Elmwood Avenue, PO Box 693, Rochester, New York 14642, USA \\ ${ }^{2}$ Center for Human Reproduction, New York, New York 10021, USA
}

Correspondence should be addressed to A Sen

Email

aritro_sen@urmc.

rochester.edu

\begin{abstract}
For many decades, elevated androgens in women have been associated with poor reproductive health. However, recent studies have shown that androgens play a crucial role in women's fertility. The following review provides an overall perspective about how androgens and androgen receptor-mediated actions regulate normal follicular development, as well as discuss emerging concepts, latest perceptions, and controversies regarding androgen actions and signaling in the ovary.
\end{abstract}

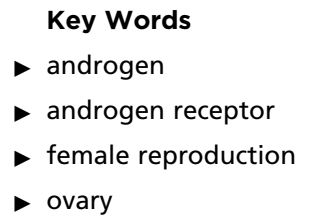

Journal of Endocrinology (2014) 222, R141-R151

\section{Introduction}

Recently, there has been a lot of interest towards the role of androgens in the regulation of follicular development and female fertility. In fact, over the years our understanding of the effects of androgens on follicular development and female fertility has undergone considerable change. Androgens have traditionally been considered detrimental to ovarian function and are often associated with infertility. However, development of different types of androgen receptor (AR) knockout mouse models, along with various in vivo and in vitro studies, as well as clinical reports, has established a new concept that sufficient androgen actions through the AR is necessary for normal follicle development and function. Consequently, it is now increasingly realized that, likely, a critical balance exists between the essentiality of androgens in normal follicular development and their detrimental effects in hyper-androgenic conditions that regulate female fertility. While androgen excess enhances follicular development and dysfunctional formation of antral follicles leading to polycystic ovary syndrome (PCOS), low androgen levels may be associated with abnormalities of follicular growth, low functional ovarian reserve (LFOR) and primary ovarian insufficiency (POI), thereby negatively impacting female fertility. Many studies (Kimura et al. 2007, Walters et al. 2008, 2010, Gleicher et al. 2011, Sen \& Hammes 2011, Lebbe \& Woodruff 2013) in the past 5 years have addressed androgen actions in the ovary. In this review, we summarize what currently is known about the direct physiological actions of androgens in the regulation of normal follicular development, and provide the molecular and/or signaling basis of these androgen actions. We also highlight the ranging controversy regarding the use of androgens as a treatment option in LFOR/POI patients.

\section{AR expression and regulation}

The idea that androgens might regulate follicular development initially started with studies in the mid- and late 1990s looking at AR expression in the ovary. Studies across species reported that ARs are expressed in theca cells, granulosa cells (GCs), and the oocyte of the follicle and throughout most stages of follicular development (Horie et al. 1992, Chadha et al. 1994, Hirai et al. 1994, Suzuki et al. 1994, Tetsuka \& Hillier 1996, Hillier et al. 1997, Szoltys \&

Published by Bioscientifica Ltd 
Slomczynska 2000, Slomczynska \& Tabarowski 2001, Gill et al. 2004, Hampton et al. 2004, Juengel et al. 2006). However, their expression patterns may differ between ovarian cell types (Tetsuka \& Hillier 1996, Szoltys \& Slomczynska 2000) and in most species, AR is abundant in the preantral/antral stages of follicular development but declines as follicles mature to the preovulatory stage (Horie et al. 1992, Chadha et al. 1994, Suzuki et al. 1994, Hillier et al. 1997, Weil et al. 1998, Duffy et al. 1999, Slomczynska et al. 2001, Cardenas \& Pope 2002, Hampton et al. 2004, Juengel et al. 2006). In fact, AR is expressed in cell-specific regions of human ovarian follicles at all stages of follicular development beyond the primordial phase (Rice et al. 2007). Based on these AR expression pattern studies, it was suggested that androgens through an autocrine and/or paracrine effect might differentially regulate various stages of follicular development. What exactly regulates AR expression in the follicle is not yet clear. Studies in primates (Weil et al. 1998) demonstrate that androgens (testosterone) in a positive feedback loop increases AR expression in the theca and GCs of preantral follicles, while studies in rats have shown that AR expression is developmentally regulated (Tetsuka et al. 1995). The general sense is that, as follicles grow from the pre-antral to the antral/preovulatory phase, the AR expression decreases, and the dominant steroid receptor shifts from AR to estrogen receptor.

\section{Stimulatory effects of androgens in follicular development}

Looking at different aspects of follicular development following androgen stimulation in various species, in vivo and in vitro studies in the late 1990s and early 2000s first demonstrated direct androgen effects in folliculogenesis. In rodents, androgen treatment enhances pre-antral follicular development and improves ovulatory response by increasing GC proliferation and attenuating follicular atresia (Mori et al. 1977, Ware 1982, Wang et al. 2001, Sen et al. 2014). Moreover, in vitro culture of whole mouse follicles in presence of androgens significantly increases the diameter of immature follicles and enhances the development of preantral follicles (Murray et al. 1998, Wang et al. 2001, Sen et al. 2014). In large farm animals, in vivo administration of testosterone was shown to stimulate the transition of follicles from primary to secondary stage (Hampton et al. 2004, Yang \& Fortune 2006) and to increase the number of ovulatory follicles and corpora lutea (Cardenas \& Pope 1994, Cardenas et al. 2002, Hickey et al. 2004, 2005). Finally, administration of androgens in monkey (Abbott et al. 1998, Vendola et al. 1998) and ewes (Smith et al. 2009) demonstrated initiation of follicular recruitment, stimulation of early stages of follicular growth, and increase in the number of growing follicles. Importantly, in all these studies, it was demonstrated that the observed androgenic effects could be blocked by anti-androgens (Peluso et al. 1981, Murray et al. 1998, Yang \& Fortune 2006). Despite all of these studies, the question still remained whether these reported androgen actions are the consequence of direct androgen actions via the AR or due to aromatization of androgens to estrogen.

\section{AR knockout mouse models}

Earlier, it was believed that androgens affect ovarian function either by acting as a precursor of steroidogenesis (specifically by aromatization to estrogen) or by indirect effects mediated by the hypothalamus-pituitary axis or metabolic tissues. The development of the global AR knockout (ARKO) female mouse models in the mid- and late 2000 established the importance of direct androgen action through ARs in normal female reproduction. The first Ar-null model (Lyon \& Glenister 1974) carried homozygous mutation in the testicular feminization (Tfm) $A r$ gene on the $\mathrm{X}$ chromosome $\left(A r^{\mathrm{tfm}} / A r^{\mathrm{tfm}}\right)$. $A r^{\mathrm{tfm}} / A r^{\mathrm{tfm}}$ mice ovulated, mated, and maintained pregnancies, but demonstrated significantly reduced reproductive performance (Lyon \& Glenister 1980). As the $A r$ gene is located on the $\mathrm{X}$ chromosome and males lacking functional $\mathrm{Ar}$ are infertile, homozygous female offspring lacking functional $A r$ were difficult to generate.

Later, however, using the Cre/LoxP system, three different global ARKO models were, nevertheless, generated by targeting deletion of exons $1\left(A r_{1}^{-/-}\right)$(Shiina et al. 2006), exon $2\left(A r_{2}^{-1-}\right)$ (Hu et al. 2004), or exon $3\left(A r_{3}^{-1-}\right.$ ) (Walters et al. 2007) of the AR, leading to either the loss of $\mathrm{AR}$ protein (in $\mathrm{AR}_{1}^{-/-}$and $\mathrm{AR}_{2}^{-1-}$ ) or to a nonfunctional AR protein (in $\mathrm{AR}_{3}^{-1-}$ ). All of these $A r$-null female mice were demonstrated to have normal ovarian and oviductal morphology but reduced fertility, with $A r_{1}^{-/-}$and $A r_{2}^{-1-}$ exhibiting a mildly more severe phenotype than $\mathrm{Ar}_{3}^{-1-}$. All three models are, however, distinctively sub-fertile, with smaller litter size, less corpora lutea, higher atretic follicle rates, and development of POI.

Given that ARs are expressed in all three components of the hypothalamus-pituitary-ovarian axis (Sullivan \& Moenter 2004, Dart et al. 2013), two cell-specific (oocyte- and GC targeted) ARKO mice have been generated by crossing $A r$ (exon 2)-floxed mice with either growth-differentiation factor 9 (GDF9)-Cre or

Published by Bioscientifica Ltd 
anti-Müllerian hormone receptor type 2 (AMHR2)-Cre mice, respectively, to determine whether ovarian androgen activities are critical for normal female fertility (Sen \& Hammes 2010). The oocyte-specific ARKO model has no reproductive phenotype, suggesting that, in the mice, androgen activity in oocytes is not necessary for normal female fertility. In contrast, the GC-specific ARKO model display reduced reproductive function in a very similar way to the global ARKO mice phenotype. The GC-specific ARKO mice are sub-fertile with longer estrus cycles and lower numbers of litters per female, have fewer ovulated oocytes with smaller litter sizes, and experience high rate of follicular atresia ultimately leading to early infertility. In addition, the ovaries from GC-specific ARKO mice contain more pre-antral and atretic follicles, with fewer antral follicles and corpora lutea. Finally, in vitro growth of follicles from GC-specific ARKO mice is slower than that of follicles from wild-type animals (Sen \& Hammes 2010). These results suggest that, specifically in GCs, androgen activities regulate follicle progression from pre-antral stage into the antral stage. In absence of functional ARs in GCs, pre-antral follicles become atretic instead of developing into follicles that can be ovulated to produce corpora lutea (Fig. 1).

An additional GC-specific ARKO has been generated recently by crossing AR (exon 3)-floxed mice with the AMH-Cre mice (GC-ARKO) (Walters et al. 2012). Similar to the first GC-specific ARKO (Sen \& Hammes 2010), this GC-ARKO female mouse model is subfertile, with longer estrous cycles, more atretic follicles, and fewer litters and pups. In addition, these animals show decreased cumulus cell expansion and lower rates of fertilization, confirming in normal female fertility the importance of selective AR-mediated activities in GCs. GC-ARKO mice, however, exhibit less potent ovarian phenotypes, with no depletion of antral follicles and no reduction in corpora lutea. The main difference between these two GC-specific ARKO models is that in the first generated GC-specific ARKO mouse model GC-AR expression is completely lost, while the second (GC-ARKO) model retains a nonfunctional AR protein. Whether this truncated AR protein is still capable of inducing non-genomic/membrane-initiated signaling and thereby still can influence follicular development in the ovary remains to be determined.

The picture now evolving, based on all these studies for two decades, is that androgens are essential drivers of early follicular stage development, and are not just precursors of steroidogenesis in the later stages of folliculogenesis. It is now generally accepted that androgens primarily affect pre-antral follicles, and that their activities are important for pre-antral follicle growth and prevention of follicular atresia (Fig. 1). Though still lacking substantial evidence, a perception has recently arisen that androgens, in addition, may also be involved in activation of primordial follicles (Fig. 1). However, only few studies have so far suggested this concept (Abbott et al. 2005, Smith et al. 2009, Magamage et al. 2011), and in global and GC-specific ARKO mouse models, the number of primordial follicles was normal. Therefore, it is possible that androgens may not be essential for primordial
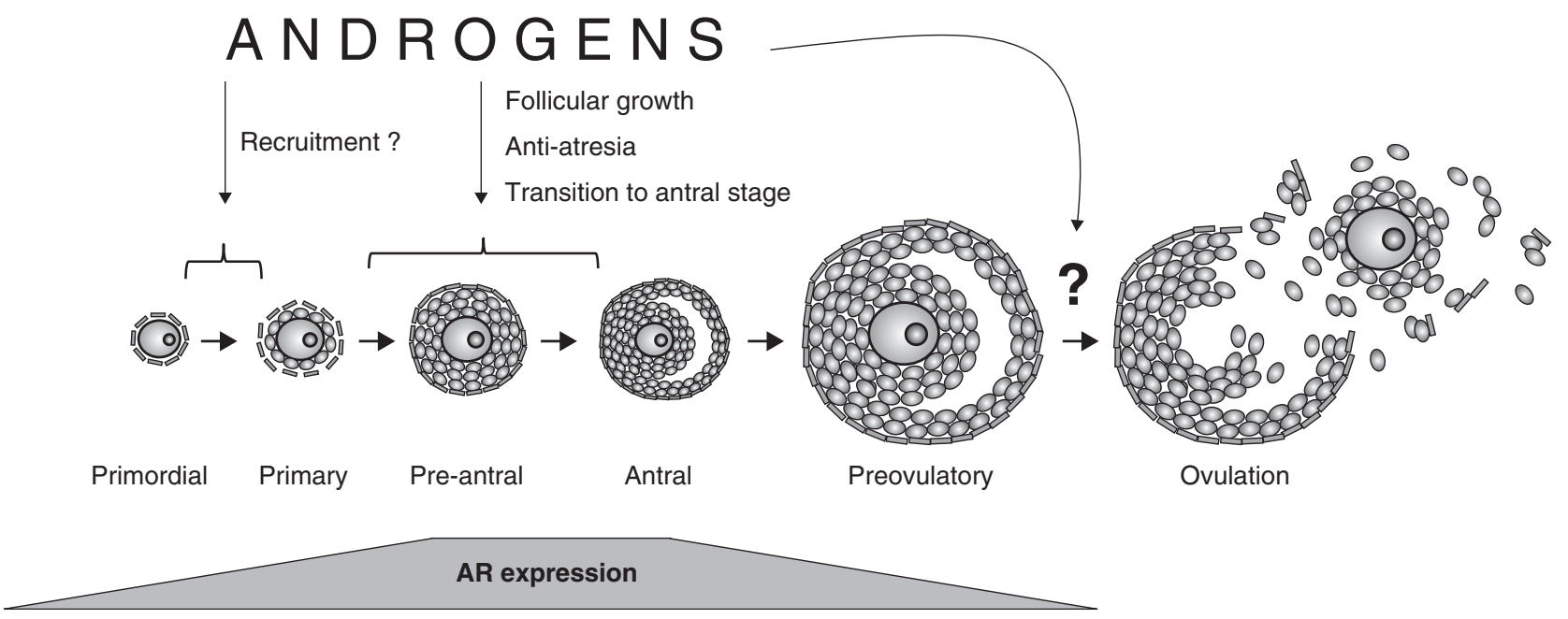

Figure 1

Physiological actions of androgens in follicular development. Androgens through androgen receptors directly regulate pre-antral follicle growth, prevent follicular atresia, and are involved in antral follicle formation.
Androgens have also been proposed to play a role in primordial follicle recruitment as well as in the ovulation process. However, further studies are needed to establish these proposed androgen actions. http://joe.endocrinology-journals.org DOI: 10.1530/JOE-14-0296
(C) 2014 Society for Endocrinology Printed in Great Britain
Published by Bioscientifica Ltd. 
follicle recruitment but may promote primordial follicle activation. Whether and how androgens effect primordial follicle recruitment and whether this is a primary or secondary response to androgens, are thus still an open-ended question and need further investigation.

\section{Intracellular mechanisms of androgen actions in the ovary}

Although our knowledge about AR expression and physiological effects of androgens during follicular development has greatly increased, our understanding about the underlying mechanism(s) of androgen-AR interactions regulating specific aspects of follicular physiology is still limited.

\section{AR signaling}

Androgen functions are mediated via either 'nuclear/ genomic' or 'extra-nuclear/non-genomic' actions of ARs (Fig. 2). Recently (Sen et al. 2010, 2012, 2014), it has been found that androgens can promote Erk signaling via matrixmetaloproteinases (MMPs)-mediated trans-activation of the epidermal growth factor receptor (EGFR), a mechanism that is conserved from Xenopus (Rasar et al. 2006) to mice (Carbajal et al. 2011) and humans (Evaul \& Hammes 2008). These observations have given rise to the interesting concept that, outside the nucleus, androgen actions are very similar to those of growth factors. Intriguingly, a multi-domain adaptor protein, called paxillin (PXN), traditionally thought to regulate cytoskeletal remodeling and focal adhesion functions, is an essential mediator of androgen-induced Erk activation (Sen et al. 2010, 2012, 2014). Furthermore, PXN serves as a liaison between extranuclear signaling and nuclear transcription in response to androgens (Sen et al. 2012). Infact, PXN is necessary for nuclear localization of AR.

A recent study (Sen et al. 2014) has reported that the physiological effects of androgens may involve synergistic interaction between the nuclear and extranuclear signaling of ARs. Using mice GCs, a human GC tumor cell line (KGN), and primary human GCs isolated during oocyte retrieval from women undergoing in vitro fertilization, it was demonstrated that androgens, through PXNregulated genomic as well as non-genomic AR actions, induce the expression of a micro-RNA (miR-125b) that decreases pro-apoptotic proteins, thereby contributing to

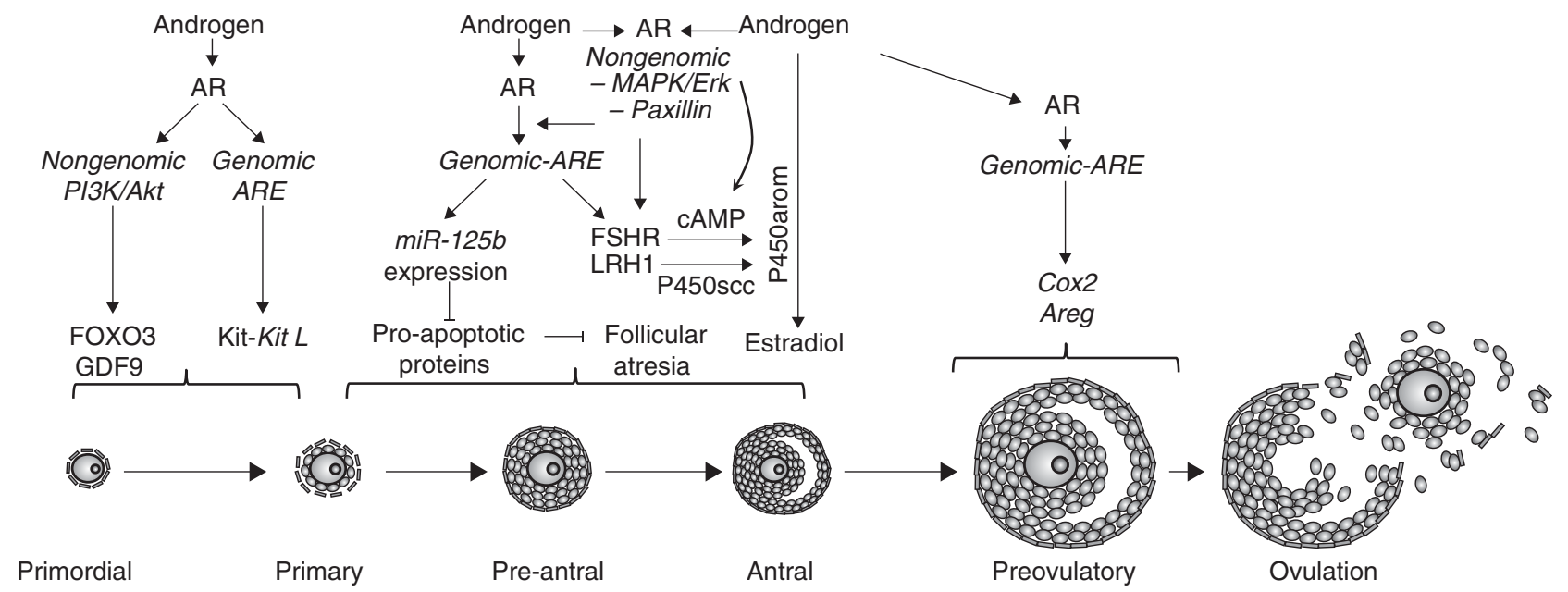

\section{Figure 2}

Underlying mechanisms of androgen actions in follicular development. Physiological functions of androgens are mediated through androgen response element (ARE)-dependent genomic actions and/or via membraneinitiated non-genomic signaling. During primordial follicle recruitment, androgens induce expression of KIT ligand. Also, it is hypothesized that the androgen receptor (AR)-induced PI3K/AKT pathway through modulation of FOXO3 and GDF9 may be involved in primordial follicle recruitment. In the pre-antral stage of follicular development, androgens through a synergistic interaction between the nuclear (ARE-dependent genomic actions) and extranuclear signaling (AR-induced Erk signaling via MMPmediated trans-activation of the EGFR), regulated by a common adaptor protein called paxillin, induce the expression of a micro-RNA ( $m i R-125 b$ ) in granulosa cells, which contribute to follicular survival by inhibiting pro-apoptotic protein levels and preventing follicular atresia. Androgens also increase FSHR and intracellular CAMP levels that enhance the sensitivity of pre-antral follicles toward FSH actions. Moreover, androgens stimulate the expression of key steroidogenic enzymes, aromatase (P450arom) and P450 side chain cleavage enzyme (P450scc) in a mechanism mediated by ARE-dependent induction of an orphan nuclear receptor, liver receptor homolog 1 (LRH1). In addition, androgens serve as a precursor of estradiol synthesis. All these androgen-AR actions together promote pre-antral follicle growth and transition to antral stage. In peri-ovulatory GCs, androgens through ARE-dependent genomic actions can induce the expression of Cox2 and Areg genes and thereby can directly influence the ovulatory process. http://joe.endocrinology-journals.org DOI: 10.1530/JOE-14-0296
(C) 2014 Society for Endocrinology Printed in Great Britain
Published by Bioscientifica Ltd 
androgen-induced follicular survival (Sen et al. 2014). Based on these observations, it has been proposed (Fig. 2) that under normal conditions in the ovary, androgens may maintain a certain level of miR-125b expression, essential for preservation of a balance between follicular survival and atresia.

\section{Androgens and follicle-stimulating hormone receptor}

In different species, it has been for a long time reported that androgens demonstrate positive correlations with follicle-stimulating hormone receptor (FSHR) levels during follicular development. A recent study in human GCs from small antral follicles has reported a positive correlation between mRNA levels of $A R$ and FSHR and androgen levels in follicular fluid (Nielsen et al. 2011). Furthermore, androgens were found to induce FSHR mRNA expression during pre-antral to antral follicle progression in several animal models, such as primates (Vendola et al. 1998, Weil et al. 1999), gilts (Cardenas et al. 2002), and bovine (Luo \& Wiltbank 2006). Whether this induction of FSHR gene expression by androgens is mediated directly through AR-androgen response elements (ARE) genomic actions or is an indirect effect of androgens, themselves, is not yet clear. In contrast, a recent study has shown that androgens increase FSHR protein levels in a transcription-independent (nongenomic) fashion (Sen et al. 2014) through a PXNdependent pathway. Despite these differences, all the studies uniformly suggest that androgen stimulation enhances follicular sensitivity toward FSH actions by increasing FSHR levels, which, potentially, contributes to follicle growth (Fig. 2). As specific AR antagonists block testosterone and dihydrotestosterone (DHT) stimulation of FSHR, this androgen-induced FSHR stimulation is specifically regulated through the AR (Luo \& Wiltbank 2006, Sen et al. 2014).

AR-induced increase in FSHR levels, in turn, indirectly modulates downstream physiological actions of the FSHR. For example, it is well established that during follicular development, FSH stimulates P450 aromatase (P450arom) expression (Hillier 1994), a key enzyme in the biosynthesis of $17 \beta$-estradiol $\left(\mathrm{E}_{2}\right)$ from androgens (Vegetti \& Alagna 2006). Therefore, androgens can indirectly modulate P450arom activity in two distinct ways: as an enhancer, by increasing FSHR expression and augmenting FSH functions; and also as a substrate of $\mathrm{E}_{2}$ synthesis (Tetsuka \& Hillier 1997).

Various studies support a direct synergism between androgens and FSH in the ovary. In mice GCs, FSH alone promoted follicular growth; however, addition of androgens significantly increased FSH-mediated follicular diameter (Wang et al. 2001, Sen et al. 2014). In addition, synergistic actions of testosterone and FSH increased P450arom expression and conversion of androgens to estrogens in the rat (Hillier \& De Zwart 1981, Fitzpatrick \& Richards 1991, Tetsuka et al. 1995), bovine (Luo \& Wiltbank 2006), and primate GCs (Weil et al. 1999) as well as in porcine (Slomczynska et al. 2003) and mice small follicles (Wang et al. 2001). In primate GCs, P450arom mRNA was selectively expressed in AR and FSHR positive follicles (Weil et al. 1999); and in rat GCs, the stimulatory effect of testosterone on P450arom in response to FSH was inhibited by thenon-steroidal anti-androgen SCH16423 (Hillier \& De Zwart 1981). Importantly, as mentioned previously, the expression of AR gradually decreases as follicles mature, whereas expression of P450arom is increased as follicular differentiation progresses (Tetsuka \& Hillier 1997, Weil et al. 1998). GCs from large preovulatory follicles, therefore, demonstrate decreased responses to FSH after androgen supplementation (Harlow et al. 1988, Hillier et al. 1988). Taken together, these results indicate that FSH-mediated P450arom induction in the ovary may be an AR-dependent and a developmental-stage regulated process (Hillier 1994).

The synergistic activity of androgen on FSH-induced actions may also lie at intracellular cyclic AMP (cAMP) level, a major intracellular mediator of FSHR signaling necessary for follicular cell proliferation and differentiation (Dorrington et al. 1983, Richards et al. 1983, Hillier 1987). Studies in rat GCs showed that testosterone stimulation of FSH-induced steroidogenesis was associated with increased cAMP accumulation in culture medium (Dorrington et al. 1983). This stimulatory effect of testosterone was again blocked by the nonsteroidal anti-androgen (SCH16423; Hillier \& de Zwart 1982). Whether these androgen actions on cAMP levels are just a secondary effect of increased FSHR or are due to direct androgen effects on cAMP level is still unclear. Some studies proposed that androgen/AR signaling may potentiate FSH-induced steroidogenesis during GC differentiation by suppressing cAMP catabolism (Hillier \& de Zwart 1982, Knecht et al. 1983, Hsueh et al. 1984).

\section{Androgens, insulin-like growth factor, and GDF9 signaling}

Androgens, acting via the AR, may regulate the expression and action of key ovarian growth factors during different stages of follicle growth. In vitro follicle culture studies in rats suggest that GDF9 promotes pre-antral to early

Published by Bioscientifica Ltd 
antral follicle transition by upregulating CYP17 expression (Vitt et al. 2000) and follicular androgen biosynthesis (Orisaka et al. 2009). In the same model system, specific AR antagonist suppressed the observed GDF9-induced pre-antral follicle growth (Orisaka et al. 2009).

In primate ovaries, in vivo treatment of both testosterone and DHT significantly enhanced insulin-like growth factor 1 (IGF1) and IGF1 receptor (IGF1R) mRNAs (Vendola et al. 1999a,b). More recently, DHT has been shown to enhance IGF1-stimulated porcine GC proliferation, by potentiating the mitogenic effects of GDF9 (Hickey et al. 2004), secreted by denuded oocytes (Hickey et al. 2005). These DHT effects were blocked by the presence of an AR antagonist (Hickey et al. 2004, 2005). A study in cultured rat pre-antral follicles, in addition, found that insulin-like 3 (INSL3), a theca cell-derived growth factor, increased testosterone production and promoted growth, an action mediated by GDF9 (Xue et al. 2014). Flutamide inhibited these effects of INSL3 on pre-antral follicular growth, suggesting that androgens are involved in GDF9- and INSL3-induced pre-antral follicular growth. All these observations indicate that an intra-ovarian growth factor system plays an essential role in ovarian follicular development, regulated by androgen/AR actions.

\section{AR-induced genes in follicular development}

Only a small number of direct AR-induced genes have unfortunately so far been identified in the ovary. They include the following:

Kit ligand (Kitl) Kitl, which is localized to oocytes and its receptor, Kit, localized to GCs, are among the first ligandreceptor systems to be identified in ovarian follicle (Motro \& Bernstein 1993, Thomas \& Vanderhyden 2006). Kitl was identified using genome-wide microarray analysis of RNA from $\mathrm{Ar}_{1}^{-1-}$ mice ovaries (Shiina et al. 2006). In primary wild-type mice GCs, DHT induced the expression of Kitl (Wu et al. 2013), whereas flutamide attenuated the induction (Shiina et al. 2006). In addition, androgeninduced transactivation of KITL promoter was observed by a luciferase reporter assay in a tumor GC KGN cell line (Shiina et al. 2006). Thus, KITL represents a direct downstream target of androgen signaling (Fig. 2).

MicroRNA-125b (miR-125b) As mentioned earlier, in primary mice GCs, androgens through extranuclear AR signaling and nuclear AR actions synergistically induce the expression of miR-125b (Sen et al. 2014). The promoter region of miR-125b contains AREs, and a ChIP assay confirmed that ARs bind to miR-125b promoter, following DHT stimulation.

Cyclooxygenase-2 (Cox2 (Ptgs)) and amphiregulin (Areg) A recent study has demonstrated that during the ovulation process the androgen-AR pathway plays a role in the last stage of folliculogenesis (Yazawa et al. 2013). In peri-ovulatory GCs, Cox2 and Areg genes were shown to contain AREs and can be induced by the DHT-AR pathway (Yazawa et al. 2013). These findings suggested that androgens, produced by the luteinizing hormone (LH) surge, are likely to act through the AR, and may be involved in the ovulatory process by directly regulating the expression of Cox2 and Areg genes and their actions.

Cyclin-dependent kinase inhibitor-1/p21 p21 is known to play a role in GC luteinization (Robker \& Richards 1998), and is downregulated in $\mathrm{Ar}_{2}^{-1-}$ mice ovaries (Hu et al. 2004). The promoter region of $\mathrm{p} 21$ contains an ARE and, therefore, the AR likely regulates its expression. The marked reduction in p21 expression in the Ar-null ovary during the peri-ovulatory stage may disturb the process of terminating proliferation and explain the increased cell apoptosis and follicular atresia in these $A r_{2}^{-1-}$ mice (Hu et al. 2004, Walters et al. 2010).

Liver receptor homolog (LRH1) The orphan nuclear hormone receptor LRH1 is expressed exclusively in GCs at all stages of follicular development (Falender et al. 2003). Interestingly, LRH1 has the ability to activate the transcription of number of steroidogenic enzymes, such as P450arom and cholesterol side-chain cleavage enzyme (P450ccc; Sirianni et al. 2002). A recent study has demonstrated that testosterone stimulated P450arom and P450scc expression in rat GCs in a mechanism mediated by LRH1 expression (Wu et al. 2011). ARE was identified in $L R H 1$ promoter that responded selectively to testosterone by AR binding. A subsequent study demonstrated that testosterone stimulated the expression of aryl hydrocarbon receptor, which then formed a complex with the AR on the LHR1 promoter (Wu et al. 2013).

These findings indicate that androgens not only synergize with FSH in the stimulation of P450arom and P450scc activity but also directly regulate their expression and, therefore, play a crucial positive stimulatory role in the differentiation process of GCs.

Published by Bioscientifica Ltd 


\section{Future direction}

The development of $A r$-knockout female mouse models, along with various in vivo and in vitro studies, has established the importance of androgens and AR-mediated actions in normal female fertility. Despite all of these studies, our understanding of how androgens regulate follicular development is still limited.

As mentioned previously, further studies are needed to elucidate how androgens may regulate primordial follicle recruitment. Another area that has received little attention to date is membrane-initiated AR signaling, its interaction with other steroids and growth factors and specific aspects of ovarian physiology regulated by AR signaling. For example, it is hypothesized (Yang et al. 2010, Lebbe \& Woodruff 2013) that the AR-induced PI3K/AKT pathway through modulation of FOXO3 and GDF9 may be involved in primordial follicle recruitment. However, further studies are needed to establish this fact. Moreover, other than the recent report that androgens may regulate FSHR levels in a transcriptionindependent fashion (Sen et al. 2014), nothing is known about the non-genomic effects of androgens and the hormone's underlying mechanism in the ovary. Many over the years have also proposed the idea that androgens may regulate $\mathrm{AMH}$ expression and/or levels (Lebbe \& Woodruff 2013). This idea comes from correlation studies showing a positive relationship between androgens and AMH levels in follicular fluid. However, direct evidence of androgeninduced AMH expression and its underlying mechanism in GCs are still lacking. One of the biggest limitations for our understanding of how androgens regulate follicular development lies in the fact that very few $A R$-dependent genes with importance in ovarian physiology have yet been identified. With focus towards differentiating extra-ovarian and intraovarian effects, and the mechanism involved, another important question that needs to be addressed is the effects of androgen on the ovulation process. Addressing these questions would not only help to gain a better understanding of how androgen signaling contributes to pathophysiological conditions, such as LFOR, POI, and PCOS but, once these clinical conditions are better understood, allow for targeted therapeutic strategies to manipulate ARmediated signaling and improve the prognosis for these common causes of infertility

\section{Clinical perspectives}

As evident from the above-mentioned scientific data, with respect to androgen effects on female fertility, 'Goldilocks' concept is the key. Too much is bad but too little is also bad
- it needs to be just right. In fact, there is evidence that androgen levels in women with LFOR are low, irrespective of age or premature ovarian aging (Gleicher et al. 2013a). It is hypothesized that this decrease in androgen level in women with LFOR is likely at least partially due to a relative adrenal insufficiency in androgen production. While androgen excess and PCOS have received a lot of focus, clinical perspectives with respect to low levels of androgens and its effect on female fertility have got little attention till date. Thus, in this section, we primarily focus on the 'too little' side of androgen levels/actions in the ovary.

In recent years, the use of androgens, specifically DHEA supplementation in women with LFOR, has gained increasing popularity around the world. The possibility that DHEA supplementation may beneficially affect women with LFOR was first suggested by Casson et al. (2000) who in a small cohort of women reported improved oocyte yields with short-term supplementation via DHEA. Thereafter, Gleicher and Barad in a series of studies with LFOR patients reported that DHEA supplementation not only improves oocyte yield but also positively affected egg and embryo quality, as well as in vitro fertilization (IVF) pregnancy rates (Barad \& Gleicher 2005, 2006, Gleicher \& Barad 2006, 2011). In recent years, many other research groups have also reported the positive effects of DHEA (Mamas \& Mamas 2009, Sonmezer et al. 2009, Wiser et al. 2010, Sunkara \& Coomarasamy 2011, Hyman et al. 2013, Yilmaz et al. 2013) and testosterone supplementation (Gonzalez-Comadran et al. 2012) on female fertility.

However, opinions are still divided on the issue of androgen treatment in LFOR patients. Initially, two main questions were raised against the idea of androgen supplementation: i) Lack of scientific evidence regarding the positive effects of androgens on ovarian physiology and ii) lack of enough rigorous randomized trials of sufficient size.

The studies mentioned earlier now quite well established the positive physiological effects of androgen supplementation on follicular development. We, recently, also started to understand the underlying cellular and molecular mechanisms of androgen supplementation at various stages of follicular development (Fig. 2). Moreover, as noted in preceding sections, it is now well recognized that androgens play a major role in follicular development and female fertility. Based on these studies, it is believed that DHEA gets metabolized to testosterone, and that the positive effects of DHEA supplementation are mediated through the AR (Fig. 3). However, not all women respond equally well to DHEA supplementation, a frequent argument against DHEA supplementation. Non-responding women apparently do not adequately

Published by Bioscientifica Ltd 


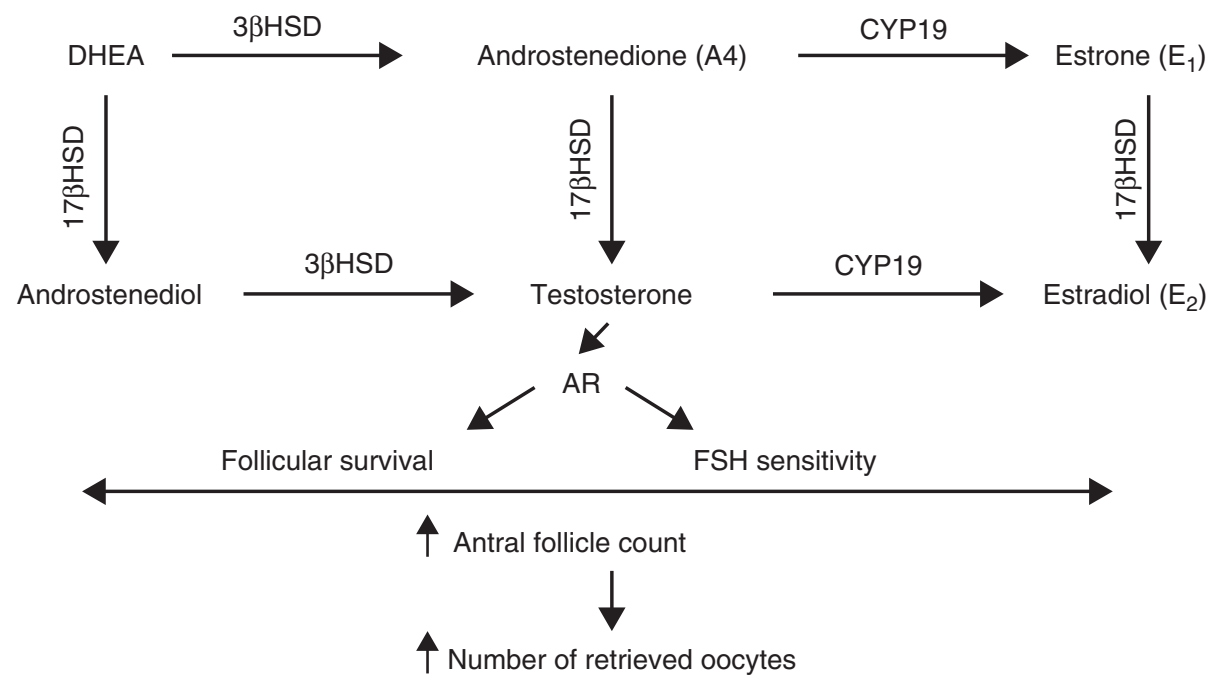

Figure 3

Proposed mode of DHEA actions in low functional ovarian reserve (LFOR) patients. Based on the studies in various animal models, it is hypothesized that when LFOR patients are supplemented with DHEA, the latter gets metabolized to testosterone. Thereafter, testosterone acting through the

convert DHEA to testosterone, a phenomenon apparently associated with advanced female age and so-called low mutations in the fragile $\mathrm{X}$ mental retardation 1 (FMR1) gene, characterized by trinucleotide repeat $\mathrm{CGG}_{n<26}$ (Gleicher et al. 2013b). Currently, a clinical trial is underway to investigate the effects of transdermal testosterone in this nonresponding patient population. Whether simply increasing serum testosterone levels is always sufficient to improve fertility in women with LFOR is still unclear. Some women may exhibit an inherent problem with respect to AR signaling. In fact, AR polymorphism and/or role of AR-spliced variants with respect to AR functions in ovarian physiology have not been studied in great details.

A counter point that has been raised against the lack of rigorous randomized trials of sufficient size involving androgen supplementation in LFOR patients is the strategic difficulty in conducting such clinical trials. It has been argued that women with LFOR, perceiving time pressure, refuse randomization to placebo. Such clinical trials, from the start, therefore, face difficulties with patient recruitment. In the U.S., another problem is that, Congress legislatively prohibits funding of all IVF-related research, and there is lack of interest by the pharmaceutical industry to support such research. As a consequence, so far, therefore, only two small, greatly underpowered clinical trials of DHEA have been published in women with LFOR (Wiser et al. 2010, Yeung et al. 2014).

Despite these concerns, it is estimated that approximately one-quarter of all IVF clinics today use DHEA androgen receptor (AR) promotes pre-antral follicular growth and survival, as well as increases the sensitivity of pre-antral-follicles toward FSH actions. All of these together increase the number of antral follicle count that ultimately leads to more number of retrieved oocytes during IVF treatment.

supplementation in women with LFOR (Sunkara et al. 2012). Regarding androgen supplementation in LFOR patients, it can, therefore, be stated that consensus has so far not been reached. As with any new emerging concept, time will be the best judge, as more and more studies from different clinical centers are published on this issue from around the world.

\section{Declaration of interest}

$\mathrm{H} P$ and $\mathrm{A} S$ have nothing to disclose. N G received in the past research and travel funds from various pharmaceutical and medical device companies, unrelated to the topics discussed in this study. He received travel funds and speaker honoraria from Sun Pharmaceutical Industries Ltd (India) to lecture on the utilization of DHEA in women with infertility. He holds a number of U.S. patents, claiming benefits on female fertility in women with LFOR from supplementation with androgens, including DHEA, and receives license fees from Fertility Nutraceuticals LLC, a supplement manufacturer. $\mathrm{He}$ is also a shareholder in this company.

\section{Funding}

This work was supported by the Foundation for Reproductive Medicine to AS (grant number 056131-002, 2014).

\section{References}

Abbott DH, Dumesic DA, Eisner JR, Colman RJ \& Kemnitz JW 1998 Insights into the development of polycystic ovary syndrome (PCOS) from studies of prenatally androgenized female rhesus monkeys. Trends in Endocrinology and Metabolism 9 62-67. (doi:10.1016/S1043-2760(98)00019-8)

Abbott DH, Barnett DK, Bruns CM \& Dumesic DA 2005 Androgen excess fetal programming of female reproduction: a developmental aetiology http://joe.endocrinology-journals.org DOI: 10.1530/JOE-14-0296
C) 2014 Society for Endocrinology Printed in Great Britain 
for polycystic ovary syndrome? Human Reproduction Update 11 357-374. (doi:10.1093/humupd/dmi013)

Barad DH \& Gleicher N 2005 Increased oocyte production after treatment with dehydroepiandrosterone. Fertility and Sterility $\mathbf{8 4}$ 756. (doi:10. 1016/j.fertnstert.2005.02.049)

Barad D \& Gleicher N 2006 Effect of dehydroepiandrosterone on oocyte and embryo yields, embryo grade and cell number in IVF. Human Reproduction 21 2845-2849. (doi:10.1093/humrep/del254)

Carbajal L, Biswas A, Niswander LM, Prizant H \& Hammeset SR 2011 GPCR/EGFR cross talk is conserved in gonadal and adrenal steroidogenesis but is uniquely regulated by matrix metalloproteinases 2 and 9 in the ovary. Molecular Endocrinology 25 1055-1065. (doi:10.1210/me. 2010-0410)

Cardenas H \& Pope WF 1994 Administration of testosterone during the follicular phase increased the number of corpora lutea in gilts. Journal of Animal Science 72 2930-2935.

Cardenas H \& Pope WF 2002 Androgen receptor and follicle-stimulating hormone receptor in the pig ovary during the follicular phase of the estrous cycle. Molecular Reproduction and Development 62 92-98. (doi:10.1002/mrd.10060)

Cardenas H, Herrick JR \& Pope WF 2002 Increased ovulation rate in gilts treated with dihydrotestosterone. Reproduction 123 527-533. (doi:10.1530/rep.0.1230527)

Casson PR, Lindsay MS, Pisarska MD, Carson SA \& Buster JE 2000 Dehydroepiandrosterone supplementation augments ovarian stimulation in poor responders: a case series. Human Reproduction $\mathbf{1 5}$ 2129-2132. (doi:10.1093/humrep/15.10.2129)

Chadha S, Pache TD, Huikeshoven JM, Brinkmann AO \& van der Kwast TH 1994 Androgen receptor expression in human ovarian and uterine tissue of long-term androgen-treated transsexual women. Human Pathology 25 1198-1204. (doi:10.1016/0046-8177(94)90037-X)

Dart DA, Waxman J, Aboagye EO \& Bevan CL 2013 Visualising androgen receptor activity in male and female mice. PLOS ONE $\mathbf{8}$ e71694. (doi:10.1371/journal.pone.0071694)

Dorrington JH, McKeracher HL, Chan AK \& Gore-Langton RE 1983 Hormonal interactions in the control of granulosa cell differentiation. Journal of Steroid Biochemistry 19 17-32. (doi:10.1016/S00224731(83)80003-X)

Duffy DM, Abdelgadir SE, Stott KR, Resko JA, Stouffer RL \& Zelinski-Wooten MB 1999 Androgen receptor mRNA expression in the rhesus monkey ovary. Endocrine 11 23-30. (doi:10.1385/ENDO:11:1:23)

Evaul K \& Hammes SR 2008 Cross-talk between G protein-coupled and epidermal growth factor receptors regulates gonadotropin-mediated steroidogenesis in Leydig cells. Journal of Biological Chemistry $\mathbf{2 8 3}$ 27525-27533. (doi:10.1074/jbc.M803867200)

Falender AE, Lanz R, Malenfant D, Belanger L \& Richards JS 2003 Differential expression of steroidogenic factor- 1 and FTF/LRH-1 in the rodent ovary. Endocrinology 144 3598-3610. (doi:10.1210/en. 2002-0137)

Fitzpatrick SL \& Richards JS 1991 Regulation of cytochrome P450 aromatase messenger ribonucleic acid and activity by steroids and gonadotropins in rat granulosa cells. Endocrinology 129 1452-1462. (doi:10.1210/endo-129-3-1452)

Gill A, Jamnongjit M \& Hammes SR 2004 Androgens promote maturation and signaling in mouse oocytes independent of transcription: a release of inhibition model for mammalian oocyte meiosis. Molecular Endocrinology 18 97-104. (doi:10.1210/me.2003-0326)

Gleicher N \& Barad DH 2006 Effects of transdermal testosterone application on the ovarian response to FSH in poor responders undergoing assisted reproduction technique - a prospective, randomized, double-blind study. Human Reproduction 21 3027; author reply 3027-3028. (doi:10.1093/humrep/del302)

Gleicher N \& Barad DH 2011 Dehydroepiandrosterone (DHEA) supplementation in diminished ovarian reserve (DOR). Reproductive Biology and Endocrinology 9 67. (doi:10.1186/1477-7827-9-67)
Gleicher N, Weghofer A \& Barad DH 2011 The role of androgens in follicle maturation and ovulation induction: friend or foe of infertility treatment? Reproductive Biology and Endocrinology 9 116. (doi:10.1186/ 1477-7827-9-116)

Gleicher N, Kim A, Weghofer A, Kushnir VA, Shohat-Tal A, Lazzaroni E, Lee HJ \& Barad DH 2013a Hypoandrogenism in association with diminished functional ovarian reserve. Human Reproduction $\mathbf{2 8}$ 1084-1091. (doi:10.1093/humrep/det033)

Gleicher N, Kim A, Weghofer A, Shohat-Tal A, Lazzaroni E, Lee HJ \& Barad DH 2013 $b$ Starting and resulting testosterone levels after androgen supplementation determine at all ages in vitro fertilization (IVF) pregnancy rates in women with diminished ovarian reserve (DOR). Journal of Assisted Reproduction and Genetics 30 49-62. (doi:10.1007/s10815-012-9890-z)

Gonzalez-Comadran M, Duran M, Sola I, Fabregues F, Carreras R \& Checa MA 2012 Effects of transdermal testosterone in poor responders undergoing IVF: systematic review and meta-analysis. Reproductive Biomedicine Online 25 450-459. (doi:10.1016/j.rbmo.2012.07.011)

Hampton JH, Manikkam M, Lubahn DB, Smith MF \& Garverick HA 2004 Androgen receptor mRNA expression in the bovine ovary. Domestic Animal Endocrinology 27 81-88. (doi:10.1016/j.domaniend.2004.01.005)

Harlow CR, Shaw HJ, Hillier SG \& Hodges JK 1988 Factors influencing follicle-stimulating hormone-responsive steroidogenesis in marmoset granulosa cells: effects of androgens and the stage of follicular maturity. Endocrinology 122 2780-2787. (doi:10.1210/endo-122-6-2780)

Hickey TE, Marrocco DL, Gilchrist RB, Norman RJ \& Armstrong DT 2004 Interactions between androgen and growth factors in granulosa cell subtypes of porcine antral follicles. Biology of Reproduction 71 45-52. (doi:10.1095/biolreprod.103.026484)

Hickey TE, Marrocco DL, Amato F, Ritter LJ, Norman RJ, Gilchrist RB \& Armstrong DT 2005 Androgens augment the mitogenic effects of oocyte-secreted factors and growth differentiation factor 9 on porcine granulosa cells. Biology of Reproduction 73 825-832. (doi:10.1095/ biolreprod.104.039362)

Hillier SG 1987 Intrafollicular paracrine function of ovarian androgen. Journal of Steroid Biochemistry 27 351-357. (doi:10.1016/00224731(87)90327-X)

Hillier SG 1994 Current concepts of the roles of follicle stimulating hormone and luteinizing hormone in folliculogenesis. Human Reproduction 9 188-191.

Hillier SG \& De Zwart FA 1981 Evidence that granulosa cell aromatase induction/activation by follicle-stimulating hormone is an androgen receptor-regulated process in-vitro. Endocrinology 109 1303-1305. (doi:10.1210/endo-109-4-1303)

Hillier SG \& de Zwart FA 1982 Androgen/antiandrogen modulation of cyclic AMP-induced steroidogenesis during granulosa cell differentiation in tissue culture. Molecular and Cellular Endocrinology 28 347-361. (doi:10.1016/0303-7207(82)90132-0)

Hillier SG, Harlow CR, Shaw HJ, Wickings EJ, Dixson AF \& Hodges JK 1988 Cellular aspects of pre-ovulatory folliculogenesis in primate ovaries. Human Reproduction 3 507-511.

Hillier SG, Tetsuka M \& Fraser HM 1997 Location and developmental regulation of androgen receptor in primate ovary. Human Reproduction 12 107-111. (doi:10.1093/humrep/12.1.107)

Hirai M, Hirata S, Osada T, Hagihara K \& Kato J 1994 Androgen receptor mRNA in the rat ovary and uterus. Journal of Steroid Biochemistry and Molecular Biology 49 1-7. (doi:10.1016/0960-0760(94)90294-1)

Horie K, Takakura K, Imai K, Liao S \& Mori T 1992 Immunohistochemical localization of androgen receptor in the human endometrium, decidua, placenta and pathological conditions of the endometrium. Human Reproduction 7 1461-1466.

Hsueh AJ, Adashi EY, Jones PB \& Welsh TH Jr 1984 Hormonal regulation of the differentiation of cultured ovarian granulosa cells. Endocrine Reviews 5 76-127. (doi:10.1210/edrv-5-1-76)

Hu YC, Wang PH, Yeh S, Wang RS, Xie C, Xu Q, Zhou X, Chao HT, Tsai MY \& Chang C 2004 Subfertility and defective folliculogenesis in female 
mice lacking androgen receptor. PNAS 101 11209-11214. (doi:10.1073/ pnas.0404372101)

Hyman JH, Margalioth EJ, Rabinowitz R, Tsafrir A, Gal M, Alerhand S, Algur N \& Eldar-Geva T 2013 DHEA supplementation may improve IVF outcome in poor responders: a proposed mechanism. European Journal of Obstetrics, Gynecology, and Reproductive Biology 168 49-53. (doi:10.1016/j.ejogrb.2012.12.017)

Juengel JL, Heath DA, Quirke LD \& McNatty KP 2006 Oestrogen receptor $\alpha$ and $\beta$, androgen receptor and progesterone receptor mRNA and protein localisation within the developing ovary and in small growing follicles of sheep. Reproduction 131 81-92. (doi:10.1530/rep.1.00704)

Kimura S, Matsumoto T, Matsuyama R, Shiina H, Sato T, Takeyama K \& Kato S 2007 Androgen receptor function in folliculogenesis and its clinical implication in premature ovarian failure. Trends in Endocrinology and Metabolism 18 183-189. (doi:10.1016/j.tem.2007.04.002)

Knecht M, Ranta T \& Catt KJ 1983 Hormonal regulation of a plasma membrane phosphodiesterase in differentiating granulosa cells. Reciprocal actions of follicle-stimulating hormone and a gonadotropinreleasing hormone agonist on cAMP degradation. Journal of Biological Chemistry 258 12420-12426.

Lebbe M \& Woodruff TK 2013 Involvement of androgens in ovarian health and disease. Molecular Human Reproduction 19 828-837. (doi:10.1093/ molehr/gat065)

Luo W \& Wiltbank MC 2006 Distinct regulation by steroids of messenger RNAs for FSHR and CYP19A1 in bovine granulosa cells. Biology of Reproduction 75 217-225. (doi:10.1095/biolreprod.105.047407)

Lyon MF \& Glenister PH 1974 Evidence from Tfm-O that androgen is essential for reproduction in female mice. Nature 247 366-367. (doi:10.1038/247366a0)

Lyon MF \& Glenister PH 1980 Reduced reproductive performance in androgen-resistant Tfm/Tfm female mice. PNAS 208 1-12.

Magamage M, Zengyo M, Moniruzzaman M \& Miyano T 2011 Testosterone induces activation of porcine primordial follicles in vitro. Reproductive Medicine and Biology 10 21-30. (doi:10.1007/s12522-010-0068-z)

Mamas L \& Mamas E 2009 Premature ovarian failure and dehydroepiandrosterone. Fertility and Sterility 91 644-646. (doi:10.1016/j.fertnstert. 2007.11.055)

Mori T, Suzuki A, Nishimura T \& Kambegawa A 1977 Evidence for androgen participation in induced ovulation in immature rats. Endocrinology 101 623-626. (doi:10.1210/endo-101-2-623)

Motro B \& Bernstein A 1993 Dynamic changes in ovarian c-kit and Steel expression during the estrous reproductive cycle. Developmental Dynamics 197 69-79. (doi:10.1002/aja.1001970107)

Murray AA, Gosden RG, Allison V \& Spears N 1998 Effect of androgens on the development of mouse follicles growing in vitro. Journal of Reproduction and Fertility 113 27-33. (doi:10.1530/jrf.0.1130027)

Nielsen ME, Rasmussen IA, Kristensen SG, Christensen ST, Mollgard K, Wreford Andersen E, Byskov AG \& Yding Andersen C 2011 In human granulosa cells from small antral follicles, androgen receptor mRNA and androgen levels in follicular fluid correlate with FSH receptor mRNA. Molecular Human Reproduction 17 63-70. (doi:10.1093/molehr/gaq073)

Orisaka M, Jiang JY, Orisaka S, Kotsuji F \& Tsang BK 2009 Growth differentiation factor 9 promotes rat preantral follicle growth by up-regulating follicular androgen biosynthesis. Endocrinology 150 2740-2748. (doi:10.1210/en.2008-1536)

Peluso JJ, Charlesworth J \& England-Charlesworth C 1981 Role of estrogen and androgen in maintaining the preovulatory follicle. Cell and Tissue Research 216 615-624. (doi:10.1007/BF00238656)

Rasar M, DeFranco DB \& Hammes SR 2006 Paxillin regulates steroidtriggered meiotic resumption in oocytes by enhancing an all-or-none positive feedback kinase loop. Journal of Biological Chemistry 281 39455-39464. (doi:10.1074/jbc.M608959200)

Rice S, Ojha K, Whitehead S \& Mason H 2007 Stage-specific expression of androgen receptor, follicle-stimulating hormone receptor, and anti-Mullerian hormone type II receptor in single, isolated, human preantral follicles: relevance to polycystic ovaries. Journal of Clinical
Endocrinology and Metabolism 92 1034-1040. (doi:10.1210/jc. 2006-1697)

Richards JS, Sehgal N \& Tash JS 1983 Changes in content and cAMPdependent phosphorylation of specific proteins in granulosa cells of preantral and preovulatory ovarian follicles and in corpora lutea. Journal of Biological Chemistry 258 5227-5232.

Robker RL \& Richards JS 1998 Hormone-induced proliferation and differentiation of granulosa cells: a coordinated balance of the cell cycle regulators cyclin D2 and p27Kip1. Molecular Endocrinology 12 924-940. (doi:10.1210/mend.12.7.0138)

Sen A \& Hammes SR 2010 Granulosa cell-specific androgen receptors are critical regulators of ovarian development and function. Molecular Endocrinology 24 1393-1403. (doi:10.1210/me.2010-0006)

Sen A \& Hammes SR 2011 Androgens: they don't just make a man out of you. Expert Review of Obstetrics \& Gynecology 6 19-22. (doi:10.1586/ eog.10.73)

Sen A, O’Malley K, Wang Z, Raj GV, Defranco DB \& Hammes SR 2010 Paxillin regulates androgen- and epidermal growth factor-induced MAPK signaling and cell proliferation in prostate cancer cells. Journal of Biological Chemistry 285 28787-28795. (doi:10.1074/jbc.M110.134064)

Sen A, De Castro I, Defranco DB, Deng FM, Melamed J, Kapur P, Raj GV, Rossi R \& Hammes SR 2012 Paxillin mediates extranuclear and intranuclear signaling in prostate cancer proliferation. Journal of Clinical Investigation 122 2469-2481. (doi:10.1172/JCI62044)

Sen A, Prizant H, Light A, Biswas A, Hayes E, Lee HJ, Barad D, Gleicher N \& Hammes SR 2014 Androgens regulate ovarian follicular development by increasing follicle stimulating hormone receptor and microRNA125b expression. PNAS 111 3008-3013. (doi:10.1073/pnas. 1318978111)

Shiina H, Matsumoto T, Sato T, Igarashi K, Miyamoto J, Takemasa S, Sakari M, Takada I, Nakamura T, Metzger D et al. 2006 Premature ovarian failure in androgen receptor-deficient mice. PNAS 103 224-229. (doi:10.1073/pnas.0506736102)

Sirianni R, Seely JB, Attia G, Stocco DM, Carr BR, Pezzi V \& Rainey WE 2002 Liver receptor homologue-1 is expressed in human steroidogenic tissues and activates transcription of genes encoding steroidogenic enzymes. Journal of Endocrinology 174 R13-R17. (doi:10.1677/joe.0. 174R013)

Slomczynska M \& Tabarowski Z 2001 Localization of androgen receptor and cytochrome P450 aromatase in the follicle and corpus luteum of the porcine ovary. Animal Reproduction Science 65 127-134. (doi:10.1016/S0378-4320(00)00225-6)

Slomczynska M, Duda M \& Sl zak K 2001 The expression of androgen receptor, cytochrome $\mathrm{P} 450$ aromatase and FSH receptor mRNA in the porcine ovary. Folia Histochemica et Cytobiologica 39 9-13.

Slomczynska M, Szoltys M, Duda M, Sikora K \& Tabarowski Z 2003 Androgens and FSH affect androgen receptor and aromatase distribution in the porcine ovary. Folia Biologica 51 63-68.

Smith P, Steckler TL, Veiga-Lopez A \& Padmanabhan V 2009 Developmental programming: differential effects of prenatal testosterone and dihydrotestosterone on follicular recruitment, depletion of follicular reserve, and ovarian morphology in sheep. Biology of Reproduction $\mathbf{8 0}$ 726-736. (doi:10.1095/biolreprod.108.072801)

Sonmezer M, Ozmen B, Cil AP, Ozkavukcu S, Tasci T, Olmus H \& Atabekoglu CS 2009 Dehydroepiandrosterone supplementation improves ovarian response and cycle outcome in poor responders. Reproductive Biomedicine Online 19 508-513. (doi:10.1016/j.rbmo.2009.06.006)

Sullivan SD \& Moenter SM 2004 Prenatal androgens alter GABAergic drive to gonadotropin-releasing hormone neurons: implications for a common fertility disorder. PNAS 101 7129-7134. (doi:10.1073/pnas. 0308058101)

Sunkara SK \& Coomarasamy A 2011 Androgen pretreatment in poor responders undergoing controlled ovarian stimulation and in vitro fertilization treatment. Fertility and Sterility 95 e73-e74; author reply e75. (doi:10.1016/j.fertnstert.2011.04.083) http://joe.endocrinology-journals.org DOI: 10.1530/JOE-14-0296 (c) 2014 Society for Endocrinology Printed in Great Britain 
Sunkara SK, Coomarasamy A, Arlt W \& Bhattacharya S 2012 Should androgen supplementation be used for poor ovarian response in IVF? Human Reproduction 27 637-640. (doi:10.1093/humrep/der464)

Suzuki T, Sasano H, Kimura N, Tamura M, Fukaya T, Yajima A \& Nagura H 1994 Immunohistochemical distribution of progesterone, androgen and oestrogen receptors in the human ovary during the menstrual cycle: relationship to expression of steroidogenic enzymes. Human Reproduction 9 1589-1595.

Szoltys M \& Slomczynska M 2000 Changes in distribution of androgen receptor during maturation of rat ovarian follicles. Experimental and Clinical Endocrinology \& Diabetes 108 228-234. (doi:10.1055/ s-2000-7747)

Tetsuka M \& Hillier SG 1996 Androgen receptor gene expression in rat granulosa cells: the role of follicle-stimulating hormone and steroid hormones. Endocrinology 137 4392-4397. (doi:10.1210/endo.137.10. 8828500)

Tetsuka M \& Hillier SG 1997 Differential regulation of aromatase and androgen receptor in granulosa cells. Journal of Steroid Biochemistry and Molecular Biology 61 233-239. (doi:10.1016/S0960-0760(97)80017-9)

Tetsuka M, Whitelaw PF, Bremner WJ, Millar MR, Smyth CD \& Hillier SG 1995 Developmental regulation of androgen receptor in rat ovary. Journal of Endocrinology 145 535-543. (doi:10.1677/joe.0.1450535)

Thomas FH \& Vanderhyden BC 2006 Oocyte-granulosa cell interactions during mouse follicular development: regulation of kit ligand expression and its role in oocyte growth. Reproductive Biology and Endocrinology 4 19. (doi:10.1186/1477-7827-4-19)

Vegetti W \& Alagna F 2006 FSH, and folliculogenesis: from physiology to ovarian stimulation. Reproductive Biomedicine Online 12 684-694. (doi:10.1016/S1472-6483(10)61080-2)

Vendola KA, Zhou J, Adesanya OO, Weil SJ \& Bondy CA 1998 Androgens stimulate early stages of follicular growth in the primate ovary. Journal of Clinical Investigation 101 2622-2629. (doi:10.1172/JCI2081)

Vendola K, Zhou J, Wang J \& Bondy CA 1999a Androgens promote insulinlike growth factor-I and insulin-like growth factor-I receptor gene expression in the primate ovary. Human Reproduction $142328-2332$. (doi:10.1093/humrep/14.9.2328)

Vendola K, Zhou J, Wang J, Famuyiwa OA, Bievre M \& Bondy CA $1999 b$ Androgens promote oocyte insulin-like growth factor I expression and initiation of follicle development in the primate ovary. Biology of Reproduction 61 353-357. (doi:10.1095/biolreprod61.2.353)

Vitt UA, McGee EA, Hayashi M \& Hsueh AJ 2000 In vivo treatment with GDF-9 stimulates primordial and primary follicle progression and theca cell marker CYP17 in ovaries of immature rats. Endocrinology 141 3814-3820. (doi:10.1210/endo.141.10.7732)

Walters KA, Allan CM, Jimenez M, Lim PR, Davey RA, Zajac JD, Illingworth P \& Handelsman DJ 2007 Female mice haploinsufficient for an inactivated androgen receptor (AR) exhibit age-dependent defects that resemble the AR null phenotype of dysfunctional late follicle development, ovulation, and fertility. Endocrinology 148 3674-3684. (doi:10.1210/en.2007-0248)

Walters KA, Allan CM \& Handelsman DJ 2008 Androgen actions and the ovary. Biology of Reproduction 78 380-389. (doi:10.1095/biolreprod.107. 064089)

Walters KA, Simanainen U \& Handelsman DJ 2010 Molecular insights into androgen actions in male and female reproductive function from androgen receptor knockout models. Human Reproduction Update 16 543-558. (doi:10.1093/humupd/dmq003)

Walters KA, Middleton LJ, Joseph SR, Hazra R, Jimenez M, Simanainen U, Allan CM \& Handelsman DJ 2012 Targeted loss of androgen receptor signaling in murine granulosa cells of preantral and antral follicles causes female subfertility. Biology of Reproduction 87 151. (doi:10.1095/ biolreprod.112.102012)

Wang H, Andoh K, Hagiwara H, Xiaowei L, Kikuchi N, Abe Y, Yamada K, Fatima R \& Mizunuma H 2001 Effect of adrenal and ovarian androgens on type 4 follicles unresponsive to FSH in immature mice. Endocrinology 142 4930-4936. (doi:10.1210/endo.142.11.8482)

Ware VC 1982 The role of androgens in follicular development in the ovary. I. A quantitative analysis of oocyte ovulation. Journal of Experimental Zoology 222 155-167. (doi:10.1002/jez.1402220207)

Weil SJ, Vendola K, Zhou J, Adesanya OO, Wang J, Okafor J \& Bondy CA 1998 Androgen receptor gene expression in the primate ovary: cellular localization, regulation, and functional correlations. Journal of Clinical Endocrinology and Metabolism 83 2479-2485. (doi:10.1210/jcem.83.7. 4917)

Weil S, Vendola K, Zhou J \& Bondy CA 1999 Androgen and folliclestimulating hormone interactions in primate ovarian follicle development. Journal of Clinical Endocrinology and Metabolism 84 2951-2956. (doi:10.1210/jcem.84.8.5929)

Wiser A, Gonen O, Ghetler Y, Shavit T, Berkovitz A \& Shulman A 2010 Addition of dehydroepiandrosterone (DHEA) for poor-responder patients before and during IVF treatment improves the pregnancy rate: a randomized prospective study. Human Reproduction 25 2496-2500. (doi:10.1093/humrep/deq220)

Wu YG, Bennett J, Talla D \& Stocco C 2011 Testosterone, not $5 \alpha$-dihydrotestosterone, stimulates LRH-1 leading to FSH-independent expression of Cyp19 and P450scc in granulosa cells. Molecular Endocrinology 25 656-668. (doi:10.1210/me.2010-0367)

Wu Y, Baumgarten SC, Zhou P \& Stocco C 2013 Testosterone-dependent interaction between androgen receptor and aryl hydrocarbon receptor induces liver receptor homolog 1 expression in rat granulosa cells. Molecular and Cellular Biology 33 2817-2828. (doi:10.1128/MCB. 00011-13)

Xue K, Kim JY, Liu JY \& Tsang BK 2014 Insulin-like 3-induced rat preantral follicular growth is mediated by growth differentiation factor 9 . Endocrinology 155 156-167. (doi:10.1210/en.2013-1491)

Yang MY \& Fortune JE 2006 Testosterone stimulates the primary to secondary follicle transition in bovine follicles in vitro. Biology of Reproduction 75 924-932. (doi:10.1095/biolreprod.106.051813)

Yang JL, Zhang CP, Li L, Huang L, Ji SY, Lu CL, Fan CH, Cai H, Ren Y, Hu ZY et al. 2010 Testosterone induces redistribution of forkhead box-3a and down-regulation of growth and differentiation factor 9 messenger ribonucleic acid expression at early stage of mouse folliculogenesis. Endocrinology 151 774-782. (doi:10.1210/en.2009-0751)

Yazawa T, Kawabe S, Kanno M, Mizutani T, Imamichi Y, Ju Y, Matsumura T, Yamazaki Y, Usami Y, Kuribayashi M et al. 2013 Androgen/androgen receptor pathway regulates expression of the genes for cyclooxygenase-2 and amphiregulin in periovulatory granulosa cells. Molecular and Cellular Endocrinology 369 42-51. (doi:10.1016/j.mce.2013.02.004)

Yeung TW, Chai J, Li RH, Lee VC, Ho PC \& Ng EH 2014 A randomized, controlled, pilot trial on the effect of dehydroepiandrosterone on ovarian response markers, ovarian response, and in vitro fertilization outcomes in poor responders. Fertility and Sterility 102 108-115. (doi:10.1016/j.fertnstert.2014.03.044)

Yilmaz N, Uygur D, Inal H, Gorkem U, Cicek N \& Mollamahmutoglu L 2013 Dehydroepiandrosterone supplementation improves predictive markers for diminished ovarian reserve: serum AMH, inhibin B and antral follicle count. European Journal of Obstetrics, Gynecology, and Reproductive Biology 169 257-260. (doi:10.1016/j.ejogrb.2013.04.003)

Received in final form 10 July 2014

Accepted 17 July 2014

Accepted Preprint published online 18 July 2014 http://joe.endocrinology-journals.org DOI: 10.1530/JOE-14-0296
() 2014 Society for Endocrinology Printed in Great Britain 